\title{
The relationship between playing violent electronic games and aggression in adolescents
}

\author{
PATRÍCIA ARRIAGA FERREIRA and JOSÉ LUÍS PAIS RIBEIRO* \\ Department of Psychology, University Lusófona of Technologies and Humanities, Lisbon \\ Portugal, and *Superior Institute of Applied Psychology, Lisbon, Portugal
}

\section{INTRODUCTION}

The concern with the effect of exposure to violent contents on behavior is not recent and has been the subject of intense research. Earlier findings on exposure to violence on television (TV) indicated that: (1) people can learn aggressive behaviors and attitudes'; (2) it may reinforce the behavior of already aggressive people; (3) it may desensitize individuals to violence, tuming them indifferent to other people's suffering ${ }^{2}$, and to an increasing acceptance of violence in real life ${ }^{3-4}$; and (4) it can lead to a distorted perception of the world, in which they overestimate their risk of victimisation $^{5}$. Berkowitz $z^{6}$ mentioned that exposure to violence in the media is most likely to increase the probability of aggressive behavior if the individuals are under the following conditions: (a) the focus of attention is directed to the aggression instead of focusing on other aspects; (b) the observed violence is not punished, nor does it have adverse consequences for the aggressor; (c) the individual identifies himself with aggressive models; and (d) the portrayal of violence is not considered inappropriate or unjustified.

Despite earlier studies on the effects of TV in Portugal that have shown a positive correlation between exposure to violent films and subsequent aggression $^{7-8}$, no social intervention has been made to change the current situation, and industries continue to profit from violence targeted at children and youths. 
With a new media culture, such as video games (VG), the research into the effects these games can have on people was renewed, mainly because the majority of users are adolescents and children who can be more susceptible to a violent content. Most recent research on the effects of playing violent VG suggests that there might be similarities and differences between this new entertainment and exposure to violent TV programs. First of all, unlike $T V$, a VG requires active involvement because of its interactive nature. Secondly, permanent attention and concentration is indispensable to play a game. Therefore, if the VG has violent contents, the attention will focus on the violent portrayals and aggressive acts. Thirdly, the player can rehearse the violent strategies and learn more effective ways to win the game, which implies the practice of violent behaviors. Fourthly, violence in VG is usually not punished but rewarded. The player only wins with aggressive behavior and loses if he/she cannot be effective with this behavior. Fifth, the fact that participants have to play an aggressive role can increase the identification with the aggressive characters in the game. Sixth, violence in VG is not considered inappropriate or unjustified. As Kinder" said: "the only moral justification that appears essential are the rules of the game" (p.28). Therefore, since in many violent games there is no option for violence, players are invited to be aggressive and not to feel responsible for their actions.

Based on these arguments, violence in VG could be more threatening compared with passive exposure to TV. Yet, on the other hand, the lack of realism in VG compared with TV programs could lessen influence. However, Kinder argues that it can lead players to conclude that violence has no harmful effects, and could contribute to a denial of the consequences and moral implications of violent behavior. Beyond these factors, it is important to note that new technologies can contribute to an increase of realism. Nevertheless, compared with TV violence, less is known about the impact of VG. Although some evidence that younger children become more aggressive after playing a violent VG, the few research results with adolescents have not demonstrated such link ${ }^{10}$.

The main purpose of this study was to explore the relationship between violence in VG and aggression in adolescents. There are different types of VG, with distinct contents and plots, which could have different effects on players. Furthermore, according to Griffith ${ }^{11}$ their choice of games could not be linked to the best sellers, and, therefore, they might prefer non-violent games. Based on these two assumptions we used an index of "Video game violence" (VGV) and choose the "shoot'em up" a "beat'em up" categories, since the plots and goals are basically the same: kill or beat the enemies to win the game. Finally, we explored sex differences in VG habits, self- 
reported measures of aggression, and we analyzed the predictor variables aggression

2.

\section{METHOD}

\subsection{Participants and Procedures}

A survey was conducted among 8th to 10 th graders at nine schools $\mathrm{i}$ Lisbon, Portugal. Questionnaires were distributed during regular classroor hours to students who agreed to participate. A total of 111 questionnaire were excluded from analysis. Of the 666 adolescents who participated $50.9 \%$ were boys $(n=239)$ and $49.1 \%$ girls $(n=327)$ between the ages of 1 . and 17 years $(M=14.12 ; D P=1.18)$. Participation was voluntary and ther were no incentives offered for participation.

\section{$2.2 \quad$ Measures}

A socio-demographic questionnaire was constructed to gather relevan descriptive information about the participants such as age, socio-economic status (SES), ethnicity, and level of education. We obtained information about their starting age with VG and time spent playing VG. For this measure, students were asked to estimate, on a scale ranging from "never" to "more than 10 hours per week", the average amount of time they spent playing VG at arcades, computers or consoles, regardless of content.

VGV was measured by the use of a checklist that contained a total of 59 popular shooting and fighting VG. Subjects were asked to rate the time they spent playing VG during the last six months. The four possible responses ranged from "never" to "whenever I can". In addition, they were requested to write down other games (of the same categories) they played during that period of time. In order to assess the violent content in the $118 \mathrm{VG}$ played by the adolescents, 12 journalists (familiarized with VG) rated the level of violence on a 5-point unipolar scale. VGV was obtained for each adolescent by multiplying the mean violence of each game with the total of time they played: $V G V=\Sigma f_{i} v_{i}$.

To measure Aggression, the Portuguese version of the Aggression Questionnaire $^{12}$ was used. This scale was created by Buss and Perry ${ }^{13}$ and contains four subscales of aggression: physical aggression, verbal aggression, anger and hostility. To measure Personality we used the Portuguese version of the Junior Eysenck Personality Questionnaire ${ }^{14-15}$, which has scales for Psychoticism, Extraversion, Neuroticism and a lie scale. 


\section{RESULTS}

The majority of adolescents are currently playing VG (94.4\%). Among the girls, $10.4 \%$ were nonplayers and only $0.9 \%$ boys reported never having played VG. Out of the total sample, $77.9 \%$ played on computers, $69.8 \%$ on consoles, whereas only $31,8 \%$ in arcades.

The results indicated sex differences in time spent playing video games per week, with boys reporting significantly more use of video games than girls with computers, $F(1,665)=84.49, p<.001$, consoles, $F(1,665)=75.94$, $p<.001$, and arcades, $F(1,665)=11.16, p<.01$. The mean starting age was 7.97 years $(S D=2.32)$, with boys starting significantly earlier than girls, $F(1$, 574 ) $=26.99, p<.001$ (boys $=7.54$ years ; girls $=8.44$ years). Using Time spent in VG as a covariate, the main effect of sex was statistically significant for VGV, $F(1,602)=182.44, p<.001$, with boys playing more violent games than giris. The MANOVA indicated an overall difference between males and females on aggression, $F(4,640)=34.52, p<.001$, based upon Wilks" Lambda. The univariate $F$ tests revealed that boys scored significantly higher on Physical, Verbal, and Total Aggression, whereas girls had significantly higher scores on Hostility and Anger.

Table 1 shows the relationship between Video game violence and aggression factors. For the overall sample, a small positive correlation between Video game violence and Physical Aggression was found, $r(624)=$ $0,24, p<0.001$, but closer examination showed that this relationship was only significant among girls, $r(292)=0,22, p<0.001$.

Table l. Correlations between Video game violence and aggression factors

\begin{tabular}{lllll}
\hline & $\begin{array}{l}\text { Physical } \\
\text { Aggression }\end{array}$ & $\begin{array}{l}\text { Verbal } \\
\text { Aggression }\end{array}$ & Anger & Hostility \\
\hline Video garne violence & & & & \\
\hline Boys & .06 & .05 & .02 & -.01 \\
Girls & $.22^{* * *}$ & .07 & .04 & .07 \\
Overall & $.24^{* * *}$ & .09 & .03 & .04 \\
\hline$* * 0<.05$ & & &
\end{tabular}

Furthermore, Multiple Linear Regression (Stepwise method) was used for girls' and boys' data to predict physical aggression, using SES, time spent playing VG, VGV, and Personality dimensions as predictor variables. The analyses showed the following (see Table 2): for girls, the regression model is significant in predicting physical aggression, accounting for $27 \%$ of the variation. Girls with higher scores on Psychoticism, lower SES, who played more violent VG and spent less time playing on computers, had the higher physical aggressiveness. For boys' data, higher scores on Psychoticism and Neuroticism, and the more time they spend in arcades playing VG, predicted 
greater physical aggression, accounting for $24 \%$ of the variation. Moreover, playing VG in arcades was predictive of total and verbal aggression for boys.

Table 2. Multiple Linear Regression Analyses (Stepwise method) for girls' and boys' Physical Aggression

\begin{tabular}{|c|c|c|c|c|c|c|}
\hline \multirow{2}{*}{$\begin{array}{c}\text { Dependent } \\
\text { Variable }\end{array}$} & \multicolumn{3}{|c|}{ Girls } & \multicolumn{3}{|c|}{ Boys } \\
\hline & Predictors & $R^{2}$ & $\beta$ & Predictors & $R^{2}$ & $\beta$ \\
\hline \multirow{9}{*}{$\begin{array}{l}\text { Physical } \\
\text { Aggression }\end{array}$} & Psychoticism & .16 & .36 & Psychoticism & .21 & .37 \\
\hline & Socio- & & & & & \\
\hline & economic & .22 & .20 & Neuroticism & .22 & .16 \\
\hline & Status $^{\mathrm{a}}$ & & & & & \\
\hline & Vidon mom & & & Time spent & & \\
\hline & violence & .25 & .21 & $\begin{array}{l}\text { playing VG in } \\
\text { arcades }\end{array}$ & .24 & .13 \\
\hline & Time spent & & & & & \\
\hline & playing VG & .27 & -.16 & & & \\
\hline & on computer & & & & & \\
\hline
\end{tabular}

Note. ${ }^{a}$ Higher scores indicate lower socio-economic status

\section{DISCUSSION}

From this survey we are able to conclude that playing VG is a popular leisure time activity amongst Lisbon adolescents. It is also possible to conclude that adolescents play VG mainly in computers and consoles, and less in arcades. This result suggests that adolescents spend more time with "home" VG.

In regard to sex differences, there was evidence that boys spent more time playing VG, and played more violent VG. Boys also started playing VG earlier than girls. These results were expected, since they have been reported in many previous studies ${ }^{16-19}$. Our results also suggest differences in the subtraits of aggression. While boys exceed girls on self-report measures of physical and verbal aggression, which represent the instrumental component of behavior, the inverse occurred with hostility and anger, the cognitive and affective domains of aggression.

The results of this study do not allow for inferences concerning causes or effects of VG. The emphasis was on the co-occurrence of playing violent VG and aggression. For the overall sample, VGV was positively related to physical aggression. Therefore, adolescents who reported playing more violent VG also reported higher rates of physical aggression. However, this association was small, suggesting that playing violent games have a very weak association with aggression. Nevertheless, the small size of this 
correlation was expected since VGV is just one of the many possible variables that could be associated with aggression, and we think other major factors (such as environmental, cultural, familial, genetic) can also have an impact on aggressive behaviors of adolescents. We also found that this correlation remained significant for girls but not for boys. In addition, VGV was a predictor of physical aggression in the female sub-sample which suggests that the distinction between playing VG in general and playing violent VG was useful. These associations may also be bi-directional. Aggressive girls are more likely to play these types of games, and/or girls who play violent games are more likely to be aggressive, suggesting a gender difference in susceptibility. This result was surprising, given that boys had higher scores on physical aggression and played more violent VG than girls. However, Winkel et al. ${ }^{20}$ suggested that VG could produce a more violent reaction in girls than in boys. This relationship also might be seen as evidence of a third variable related to both variables in question, such as an increase in arousal. According to Huesmann ${ }^{21}$ those who are less exposed to violence (in this case, girls), could be more aroused and act more aggressively. For boys, playing VG in arcades was a predictor of total, physical, and verbal aggression. This suggests that, like content, the social context may also be important to predict aggression. Since there appears to be differences in the social contexts of arcade-based and home-based $\mathrm{VG}^{22}$, this result suggests that for boys, the social context of arcades might be an important factor in determining aggression:

\section{ACKNOWLEDGMENTS}

We are grateful to the school authorities who allowed this study to take place, to school teachers who helped in the administration of questionnaires and particularly to all students for participation in this research. We also would like to thank M. B. Monteiro for a critical reading of the manuscript.

\section{REFERENCES}

1. Bandura, A., Ross, D., and Ross, S. A, 1963, Imitation of film-mediated aggressive models. Journal of Abnormal and Social Psychology, 66, 3-11.

2. Rule, B. G., and Ferguson, T. J., 1986, The effects of media violence on attitudes, emotions, and cognitions. Journal of Sacial lssues, 42, 29-50.

3. Linz, D., Donnerstein, E., and Penrod, S., 1987, Sexual Violence in the Mass Media: Social Psychological Implications. In: P. Shaver and C. Hendrick (Eds.), Review of Personality and Social Psychology (Vol. 7, 95-123). Beverly Hills: Sage Publications.

4. Straus, M. A., 1991, Discipline and deviance: Physical punishment of children and violence and other crime in aduithood. Social Problems, 38, 133-153. 
5. Gerbner, G., Gross, L., Morgan, M., and Signorielli, N., 1986, Living with television: The dynamics of the cultivation process. In: J. Bryant and D. Zillmann (Eds.), Perspectives on media effects (17-40). Hillsdale, NJ: Lawrence Erlbaum Associates.

6. Berkowitz L. B., 1993, Aggression: Its causes, consequences, and control New York: McGraw-Hill.

7. Monteiro, M.B., 1984, La constration sociale de la violence: Une perspective cognitive et developpementale. Unpublished doctoral dissertation, University Cat. De Louvain, Louvain-la-Neuve.

8. Vala, J., 1984, La Production Sociale de la Violence, Représentations et Comportements. Unpublished doctoral dissertation. University Cat. De Louvain, Louvain-la-Neuve.

9. Kinder, M., 1996. Contextualizing video game violence: From Teenage Mutant Ninja Turtles 1 to Mortal Kombat 2. In: P. M. Greenfield and R. R. Cocking (Eds.), Interacting with video: Advances in Applied Developmental Psychology (Vol. 11, 25-37). Norwood, NJ: Ablex Publishing Corporation.

10. Griffiths, M. D.. 1997, Video games and aggression. The Psychologist, 10, 397-401.

11. Griffiths, M. D. 1993, Are computer games bad for children? The Psychologist, 6, 401407.

12. Simōes, A., 1993. São os homens mais agressivos que as mulheres? Revista Portuguesa de Pedagogia, 3, 387-404.

13. Buss. A. H., and Perry, M.. 1992. The aggression questionnaire. Journal of Personality and Social Psychology. 63, 452-458.

14. Eysenck. H. J., and Eysenck. S. B. G.. 1975, Mamual of the Eysenck Personality Questionnaire (adult and junior). London: Hodder and Stoughton.

15. Fonseca. A. C.. and Eysenck. S. B. G.. 1989. Estudo interculturat da personalidade: comparaçĭo de criançass portuguesas e inglesas no EPQ-Júnior. Revista Portuguesa de Pedagogia, XXIII, 323-345.

16. Colwell. J.. Grady, C.. and Rhaiti. S.. 1995. Computer games, self-esteem and gratitication of needs in adolescents. Journal of Community \& . Applied Soctal Psychology, 5, 195-206.

17. Fling, S.. Smith. L., Rodriguez T.. Thornton. D., Atkins, E.. and Nixon. K.. 1992. Video games, aggression. and self-esteem: A survey. Social Behovior and Personality, 20, 3946.

18. Griffths. M. D.. and Hunt. N.. 1995. Computer game playing in adolescence: Prevalence and demographic indicators. Journal of Community and dpplied Social Psychology, 5. 189-194.

19. Phillips, C. A. Rolls, S. Rouse. A.., and Griffiths, Y. (1995). Home video game playing in schoolchildren: A study of incidence and patterns of play. Journal of tdolescence, 18. $687-691$.

20. Winkel, M.. Novak. D. M... and Hopson, H., 1987. Personality factors, subject gender, and the effects of aggressive video games on aggression in adolescents. Sournal of Research in Personality, 21, $211-223$.

21. Huesmann. L.R.. 1982. Television violence and agoressive behavior. In: D. Pearl. L. Bouthilet and J. Lazar (Eds.), Television and behavior: Ten years of scientific programs and implications for the 80 's (126-137). Washington, D.C.: U.S. Government Printing Office.

22. Lin, S., and Lepper, M. R, 1987, Correlates of children's usage of video games and computers. Journal of Applied Social Psychology, 17, 72-93. 